\title{
Fibronectin Mediates Adherence of Rat Alveolar Type II Epithelial Cells via the Fibroblastic Cell-Attachment Domain
}

\author{
Richard A. F. Clark, Robert J. Mason, Joy M. Folkvord, and John A. McDonald* \\ Department of Medicine, National Jewish Center for Immunology and Respiratory Medicine, Denver, Colorado 80206; *Department of \\ Medicine, Washington University Medical School, St. Louis, Missouri 63110
}

\begin{abstract}
The lung alveolar surface is composed of types I and II epithelial cells. Extremely attenuated type I cells cover $90 \%$ of the surface and are prone to necrosis during acute lung injury. After denudation of type I cells, the alveolar epithelium is restored by proliferation of type II cells. During reepithelialization in vivo the type II cells have been observed to reorganize on an extracellular matrix that contains fibronectin. We thus sought to determine whether type II cells would adhere to purified fibronectin. Adherence assays of primary rat type II cells were performed in protein-coated bacteriologic microtiter wells for $24 \mathrm{~h}$ at $37^{\circ} \mathrm{C}$. Concentrations of fibronectin from 1 to $300 \mu \mathrm{g} / \mathrm{ml}$ mediated type II cell adherence, $10 \mu \mathrm{g} / \mathrm{ml}$ gave maximal adherence, and $4 \mu \mathrm{g} /$ $\mathrm{ml}$ gave $50 \%$ maximal adherence. Adherence progressively increased from 1 to $72 \mathrm{~h}$. Adherence on fibronectin was at least $50 \%$ greater than adherence on laminin, types I and III collagen, or IV collagen. Little or no adherence was observed on bacteriologic plastic or albumin. Spreading on these various substrata paralleled adherence. Adherence to fibronectin, laminin, and fibrinogen was specifically blocked by their respective polyclonal antibodies. Monoclonal antibodies (MoAb) to the fibronectin cell-attachment domain blocked adherence to fibronectin, whereas MoAb to other domains did not. From the data reported here and the previously mentioned in vivo study we propose that fibronectin is an important functional component of the extracellular matrix that supports type II cells during alveolar reepithelialization.
\end{abstract}

\section{Introduction}

Pulmonary alveoli are lined by types I and II epithelial cells. The extremely attenuated type I cells cover $90 \%$ of the surface as a simple, nonstratified epithelium and often undergo necrosis during acute lung injury (1). After denudation of injured type I cells, alveolar type II cells repopulate the alveolar surface and differentiate into type I epithelial cells $(2,3)$. During this process of in vivo alveolar reepithelialization the type II cells appear to migrate, spread, and proliferate on a matrix containing fibronectin $(4,5)$. This observation is consonant with previous investigations that have demonstrated that a provisional fibronectin

Portions of this work were presented in abstract form at the Meeting of the American Society of Cell Biology, 18-22 November 1984, Kansas City, KS.

Address reprint requests to Dr. Clark.

Received for publication 5 March 1985 and in revised form 29 January 1986.

J. Clin. Invest.

(c) The American Society for Clinical Investigation, Inc. $0021-9738 / 86 / 06 / 1831 / 10 \quad \$ 1.00$

Volume 77, June 1986, 1831-1840 matrix is formed beneath epidermal cells (6-8) and corneal epithelial cells (9) during reepithelialization of cutaneous and corneal wounds, respectively.

These in vivo observations indicate that fibronectin is a suitable, if not critical, substrate for reepithelialization presumably by providing the right quality and quantity of adhesiveness for migrating epithelial cells. However, some previous in vitro investigations have suggested that fibronectin lacks the ability to mediate epithelial cell adhesion (10-12). Nevertheless, since the in vivo data suggest that fibronectin does play a role in reepithelialization, we sought to determine whether isolated alveolar type II epithelial cells would adhere to purified fibronectin. In this report we demonstrate that purified human plasma fibronectin mediates type II cell adherence in vitro and that this adherence occurs at or near the previously characterized fibroblastic cell-attachment domain of fibronectin.

\section{Methods}

Isolation of rat alveolar type II cells. Type II cells were freed from rat lung by tissue dissociation with porcine pancreatic elastase and were partially purified by density gradient centrifugation as described previously $(13,14)$. The specific-pathogen-free rats used in this study were obtained from Bantam Kingman, Walnut Creek, CA. Type II cells isolated by these techniques and placed into primary cultures have been shown to synthesize and secrete pulmonary surface active material (15). Primary isolates were used for all the adherence assays described in this report.

Proteins. Human plasma fibronectin (FN) ${ }^{1}$ was purified by the method of Furie and Rifkin (16) and after reduction gave two bands at $\sim 220,000$ apparent mol wt on sodium dodecyl sulfate $5 \%$ polyacrylamide gel electrophoresis (SDS-PAGE). Human plasma fibrinogen (FG) was purified as previously described by Clark et al. (17). Laminin (LM) and type IV collagen were purified from mouse EHS sarcoma as previously described $(18,19)$. These proteins were either kindly provided by Dr. George Martin or purchased from Bethesda Research Laboratories (Frederick, MD). Preparations from both sources gave identical patterns on SDS-PAGE and essentially the same results in adherence assays. Type I and III calf skin collagen was obtained from Worthington Laboratories (Freehold, NJ) or Collagen Corporation (Palo Alto, CA). Both preparations contained $~ 95 \%$ type I collagen and 5\% type III collagen and both gave similar results in adherence assays. Fetal calf serum (FCS) (Flow Laboratories, McLean, VA) used for type II cell adherence assays were depleted of fibronectin by passage over a gelatin-Sepharose 4B affinity column (20). Complete fibronectin depletion was monitored by reduced SDSPAGE and by inhibition enzyme-linked immunosorbent assay (ELISA) technique.

Preparation of plates for adherence assays. Protein-coated wells for adherence assays were prepared by adding $50 \mu \mathrm{l}$ of a $100-\mu \mathrm{g} / \mathrm{ml}$ protein (see above) in phosphate-buffered saline (PBS), pH 7.4, to bacteriologic

1. Abbreviations used in this paper: BM, basement membrane; ELISA, enzyme-linked immunosorbent assay; FCS, fetal calf serum; FG, human plasma fibrinogen; FN, human plasma fibronectin; HSA, human serum albumin; LM, laminin; SDS-PAGE, sodium dodecyl sulfate polyacrylamide gel electrophoresis. 
plastic, $6 \mathrm{~mm}$ diameter, flat-bottom microtiter wells (Linbro Scientific, Hamden, CT ) and incubating for $2 \mathrm{~h}$ at $22^{\circ} \mathrm{C}(21,22)$. Since some plastic protein-binding sites may still be available after application of the first protein coat, we added $50 \mu \mathrm{l}$ of $20 \mathrm{mg} / \mathrm{ml}$ human serum albumin (HSA) (Calbiochem-Behring Corp., La Jolla, CA) in PBS to each well and incubated for an additional $2 \mathrm{~h}$ at $22^{\circ} \mathrm{C}$ to block these sites (23). In some wells, a third solution of $100 \mu \mathrm{g} / \mathrm{ml} \mathrm{FN}$ or $100 \mu \mathrm{g} / \mathrm{ml} \mathrm{LM}$ was added as above for surface adsorption. Since plastic protein-binding sites were blocked by HSA, these final proteins should interact with first coat pro- teins to become bound in the wells. Wells were washed between coatings three times with PBS and could be stored in PBS for up to $24 \mathrm{~h}$ at $4^{\circ} \mathrm{C}$ without effect on adherence assays. For blocking experiments, antibodies were added to the coated wells and incubated overnight at $4^{\circ} \mathrm{C}$. Plates incubated with polyclonal antibodies were washed and used immediately, whereas plates containing monoclonal antibodies were used with the antibodies still present.

ELISA. An indirect inhibition ELISA (24) measures the amount of antigen in solution. Specific antibody is preincubated with an unknown
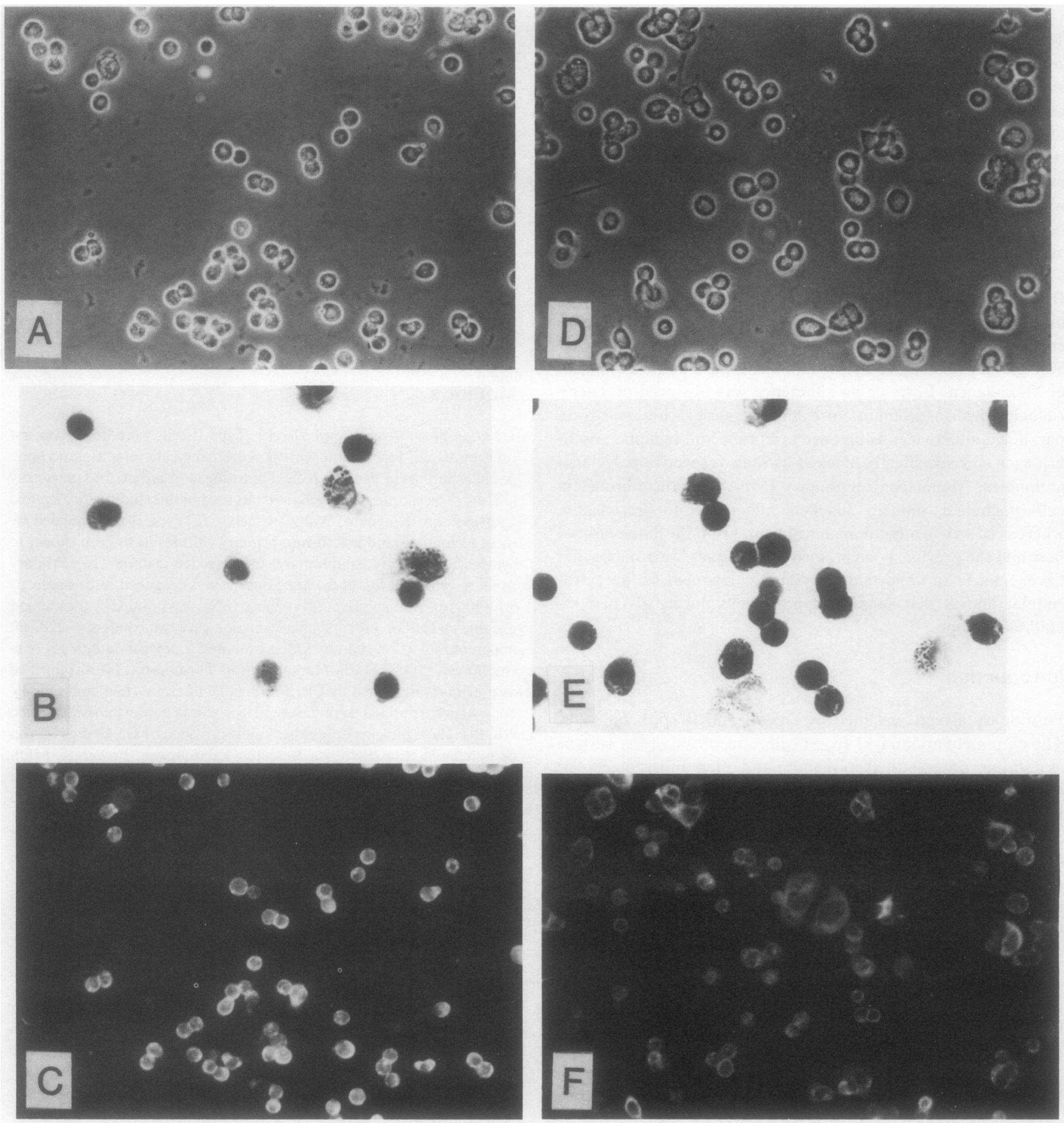

Figure 1. Photomicrographs of adherent rat lung type II epithelial cells on FN substrate at $3 \mathrm{~h}(A-C), 6 \mathrm{~h}(D-F)$, and $24 \mathrm{~h}(G-I)$ after plating observed at 2,700 magnification with phase optics $(A, D, G)$, observed at 6,000 magnification with Papanicolaou stain $(B, E, H)$, and observed at 2,700 magnification with direct immunofluorescence technique for keratin $(C, F, I)$. 
concentration of antigen and then transferred to an ELISA plate onto which the same antigen has been adsorbed. A second enzyme-conjugated antibody to the first antibody is added to the ELISA plate and then an enzyme substrate is added. The colored product is read on a spectrophotometer. The greater the antigen concentration in the preincubation solution the less color will be developed from the residual antibody. The exact concentration is determined from a standard curve of known antigen concentrations in the preincubation solution.

To prepare ELISA plates 96-well microtiter plates (Becton Dickinson Labware, Oxnard, CA) were preincubated with antigen (FN or LM) at a concentration of $2 \mu \mathrm{g} / \mathrm{ml}$ in a carbonate-bicarbonate coating buffer,
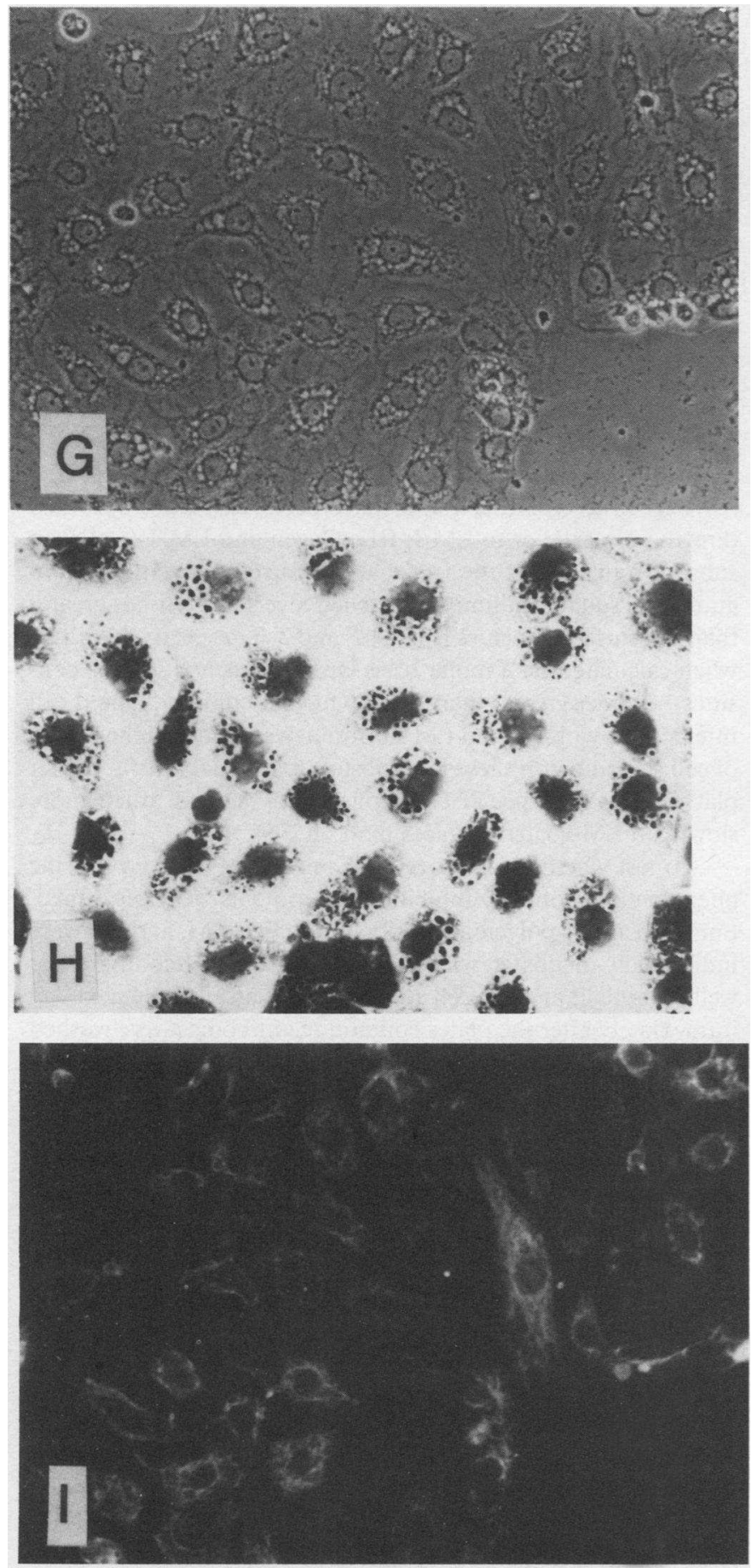

Figure 1 (continued).
pH 9.6. Wells to be used as blanks were coated with $100 \mu \mathrm{l}$ of buffer alone, and $100 \mu \mathrm{l}$ of antigen were added to the remaining wells. The plate was incubated overnight at $4^{\circ} \mathrm{C}$ for adsorption of the antigen onto the wells and then the antigen was removed. Further protein adsorption to the plastic was blocked by incubating with $200 \mu$ l of either $10 \%$ bovine serum albumin (BSA) (Sigma Chemical Co., St. Louis, MO) (for FNcoated plates) or $20 \%$ goat serum (for LM-coated plates) in coating buffer. The plate was incubated for $1 \mathrm{~h}$ at room temperature on a bench-top rocker (LabQuake, Berkeley, CA). The wells were then rinsed three times with PBS-Tween 20.

For standard curves specific antibodies were incubated with or without various amounts of soluble antigens. The final antibody concentrations were 1:20,000 for anti-FN, and 1:8,000 for anti-LM. All antigen and antibody dilutions were done in PBS with $0.05 \%$ Tween 20 . A constant amount of antibody was added to each antigen-containing solution so that the final volume was $0.44 \mu \mathrm{l}$. These solutions were incubated overnight at $4^{\circ} \mathrm{C}$.

To measure the residual antibody an aliquot of $100 \mu \mathrm{l}$ of the preincubation solution (see above) was added to the antigen-coated plate, and incubated for $30 \mathrm{~min}$. This allowed the antibodies not complexed to antigen in solution to bind the adsorbed antigen in the wells. The plate was rinsed as previously described, and a peroxidase-conjugated antibody to the first antibody was added. This second antibody was diluted $1: 1,000$ in PBS-Tween 20, added in 100- $\mu$ l aliquots, and incubated for $45 \mathrm{~min}$. The plate was rinsed three times with PBS-Tween 20 and three times with PBS, leaving the final rinse on the wells for $10 \mathrm{~min}$ in each case. Then $50 \mu \mathrm{l}$ of the enzyme substrate solution, consisting of $10 \mathrm{mg}$ $O$-phenylenediamine (Sigma) in $25 \mathrm{ml}$ citrate-phosphate buffer containing $0.1 \mathrm{M}$ citric acid, $0.2 \mathrm{M}$ sodium phosphate, and $10 \mu \mathrm{l}$ hydrogen peroxide (Sigma) was added to each well and incubated 10-30 min in the dark. This reaction was stopped by adding $50 \mu \mathrm{l}$ per well of a $2.5 \mathrm{~N}$ sulfuric acid solution. The plate was read on an ELISA reader (Biotek Instruments, Burlington, VT) for optical density at $490 \mathrm{~nm}$.

Modification of ELISA to determine protein surface density. The inhibition ELISA was used to determine the amount of FN and LM adsorbed onto the bacteriologic plastic used for type II cell adherence assays. Various concentrations of FN or LM were added to bacteriologic plastic, 24-well (each well is $16 \mathrm{~mm}$ diam), flat-bottom plates (Linbro Scientific) in the same volume to surface ratios as described for the 6$\mathrm{mm}$ diam, flat-bottom wells in the previous section. After the blocking step with albumin, antibodies to either FN at a 1:20,000 dilution, or LM at a 1:8,000 dilution, were added to the wells. The plates were incubated overnight at $4^{\circ} \mathrm{C}$, allowing the antibodies in solution to complex with the antigen adsorbed onto the wells. The next day residual antibodies were transferred from the adherence assay plates to ELISA assay plates. The amount of antibody bound was quantitated as described above. The amount of protein adsorbed onto the adherence assay plates was determined by comparing the reduction in antibody concentration that occurred after preincubation with protein-coated adherence assay plates to the reduction in antibody concentration that occurred when antibodies were preincubated with known amounts of protein in solution. Wells with larger surface areas were needed in the ELISA assay so that the total quantity of adsorbed protein was detectable. Since the polystyrene plastic used to produce the 24-well plates and the microtiter plates was identical, we assumed that the nanogram per square millimeter adsorbed protein derived from the inhibition ELISA assays in 24-well plates was identical to the surface density of adsorbed protein in the microtiter plates.

Adherence assays. Primary isolates of rat alveolar type II cells for adherence assays were washed twice in Hanks' balanced salt solution without calcium or magnesium, counted and plated into precoated wells as 100- $\mu \mathrm{l}$ aliquots of $6 \times 10^{5} \mathrm{cell} / \mathrm{s} / \mathrm{ml}$ in Eagle's minimal essential medium (Flow Laboratories) and $10 \%$ fibronectin-depleted fetal calf serum (FCSFN). All assays except the time course study and the monoclonal antibody blocking study were incubated for $24 \mathrm{~h}$ in $95 \%$ air, $5 \% \mathrm{CO}_{2}$, and $100 \%$ humidity at $37^{\circ} \mathrm{C}$.

In most assays after nonadherent cells were rinsed free, nuclei of attached cells were harvested in a solution of Isoton (Fisher Scientific, Englewood, CO) and Zapoglobin (Coulter Diagnostic, Houston, TX) 
and counted on a Coulter Counter (25). The total number of cells added to microtiter wells was counted prior to plating. Percent adherence was calculated by dividing the counts harvested by total counts added to each well $\times 100$.

In assays involving antibodies, protein-coated plates incubated with antibodies alone gave high background particle counts on the Coulter secondary to antigen-antibody aggregates preventing the use of this counting technique. Thus, in antibody blocking experiments direct visual counts of adherent cells were determined. After the cell adherence incubation period, plates were rinsed, fixed in cold methanol for $5 \mathrm{~min}$ and stained for $30 \mathrm{~min}$ with Giemsa stain diluted 1:10 (Fisher). The plates were rinsed again, dried, and cells quantified by counting 10 random, $1.7 \mathrm{~mm}^{2}$ fields per well. Percent baseline adherence was calculated by dividing the cell counts from the wells containing antibody by the cell counts from wells with no antibodies $\times 100$.

Antibodies for ELISA and blocking experiments. Antiserum to FN was raised in rabbits and antiserum to $L M$ was raised in sheep according to the methods of Crowle (26). Antibodies were purified by DEAE chromatography and $\left(\mathrm{NH}_{4}\right)_{2} \mathrm{SO}_{4}$ precipitation of antiserum (27). Anti-FN antibodies were further purified by affinity absorption with FN-free serum and FG bound to 4B Sepharose. These antibodies showed no crossreactivity by immunoprecipitation reactions and were monospecific by radial immunodiffusion assays against human plasma, human epidermal cell extracts, purified human plasma FN, and purified mouse LM. In addition, immunoblots with anti-FN against reduced human plasma and human epidermal cell extracts after 5\% SDS-PAGE showed only one band at 220,000 and 250,000 , respectively, the molecular weights for monomeric plasma and cellular FN. Monoclonal antibodies were prepared to various FN domains as previously described (28). Polyclonal antibodies to human FG were purchased from Cappel Laboratories (Cochranville, PA).

\section{Results}

Adherent rat lung cell isolates were characterized as to cell type and degree of spreading at 3, 6 and $24 \mathrm{~h}$ after plating into fibronectin-coated microtiter wells (Fig. 1). We used the modified Papanicolaou stain (29) to identify type II cells (14) and rabbit anti-keratin antibodies, kindly provided by T.-T. Sun, Department of Biochemistry, New York University, to identify epithelial cells $(30,31)$. As shown in Fig. $1 B$, most $(64 \%)$ adherent cells, even at $3 \mathrm{~h}$, were type II epithelial cells as judged by modified Papanicolaou stain. The percent adherent cells that were type II cells increased to $88 \%$ by $24 \mathrm{~h}$ (Fig. $1 \mathrm{H}$ ). Since nearly all adherent cells $(95 \%)$ at all time points were epithelial cells as judged by indirect immunofluorescence with antikeratin antibodies $(30,31)$ (Figs. $1 C, 1 F, 1 I$ ), the majority of adherent, non-type II cells were presumably either airway epithelial cells or alveolar type I cells. The remaining 5\% adherent, nonepithelial cells in these experiments were probably alveolar macrophages. Thus, at $24 \mathrm{~h}$ adherent cells consist of $88 \%$ type II epithelial cells, $7 \%$ non-type II epithelial cells, and 5\% other cell types. Therefore, in this paper most adherence assays were incubated for $24 \mathrm{~h}$ and the adherent cell population was designated type II cells for simplicity. Cells had begun to spread by $3 \mathrm{~h}$ (Fig. 1 $A$ ) but they showed marked increased spreading by $24 \mathrm{~h}$ (Fig. 1 $G)$. The kinetic response of type II cell adherence to bacteriologic plastic coated with FN, laminin, types I and III collagen, or type IV collagen, all at $100 \mu \mathrm{g} / \mathrm{ml}$, followed by HSA at $20 \mathrm{mg} / \mathrm{ml}$ or HSA alone at $20 \mathrm{mg} / \mathrm{ml}$ is shown in Fig. 2. Type II cells adhered slowly to FN with maximal adherence not obtained until 6 to $24 \mathrm{~h}$ of incubation in any experiment. The cells adhered even more slowly to laminin and type I and III collagen, and did not adhere at all to HSA and type IV collagen. In two other exper- iments, type II cell adherence on FN increased slightly between 6 and $24 \mathrm{~h}$.

Type II cell adherence onto FN-coated, bacteriologic plastic, microtiter wells was quantitated as a function of FN concentration added to precoat each well, and compared to type II cell adherence onto wells coated first with types I and III collagen or type IV collagen and then with FN (Fig. $3 A$ ). Since many more cells adhered to FN adsorbed directly to plastic than to FN/I, III collagen or FN/IV collagen substrates, we examined whether the surface density of FN adsorbed directly to plastic was higher than the FN surface density of FN/collagen substrata. Indeed, the FN surface density (nanograms per square millimeter) (as determined by a modified inhibition ELISA) on bacteriologic plastic rapidly increased as increasing FN concentrations (micrograms per milliliter) were added to precoat the wells while the FN surface density on type IV collagen coated wells was fixed at a low level for all FN concentrations added (Fig. 3 $B$ ). Thus, type II cell adherence on FN and FN/IV collagen seemed to parallel the FN surface density of these two substrata (Fig. $3 A$ and $B$ ). In contrast, the FN surface density (nanograms per square millimeter) on types I and III collagen coated wells rapidly increased for increasing FN concentrations (micrograms per milliliter) added, and yet type II cells adhered poorly to this substrate even at high FN surface densities (Fig. $3 A$ and $B$ ).

Type II cell adherence onto LM-coated, bacteriologic plastic, microtiter wells was quantitated in an identical fashion (Fig. 4 $A$ ) as the adherence of FN-coated wells described above (Fig. 3 $A$ ). Very little type II cell adherence occurred to LM adsorbed directly to plastic or to LM/I, III collagen and LM/IV collagen substrates in spite of the fact that LM surface densities (nanograms per square millimeter) reached levels three times greater than FN surface densities (Figs. $4 B$ and $3 B$, respectively). Even when calculated on a molar basis laminin reached surface densities 1.5 times greater than FN. To further compare type II cell interactions with FN and LM substrata, we examined the degree of cell spreading on these two substrates at 6,24 , and $48 \mathrm{~h}$ after plating (Fig. 5). Type II cells consistently spread much more slowly on LM-coated surfaces than on FN.

To test whether type II cell adherence to $\mathrm{FN}$ was a specific phenomenon, antibody inhibition experiments were performed. For these assays polyclonal antibodies to FN, LM, and FG were individually incubated with FN-, LM-, or FG-coated microtiter wells overnight at $4^{\circ} \mathrm{C}$. Cell adherence was assayed the next day immediately after the plates containing antibodies were washed with PBS. As shown in Fig. 6, antibodies to FN completely prevented type II cell adherence to FN-coated wells, whereas they did not affect cell adherence to LM- or FG-coated wells. Conversely, antibodies to LM or FG totally blocked cell adhesion to $\mathrm{LM}$ and FG, respectively, but not to the other substrates (Fig. 6).

When short incubation times $(3 \mathrm{~h})$ were used for cell adherence assays monoclonal antibodies (MoAb) to the fibroblastic cell-binding region (M3G) specifically blocked type II cell adherence to FN while MoAb to other FN domains did not (Fig. $7 A$ and $B$ ). During longer incubation times $(24 \mathrm{~h})$ no MoAb appeared to interfere with cell adherence (Fig. 7, $C$ and $D$ ). Likewise, polyclonal anti-FN antibodies (I-44) had more capacity to inhibit adherence when the adherence assay was incubated for a short time or when the wells were coated with less concentrated FN solutions. In addition, no inhibition was obtained when the 


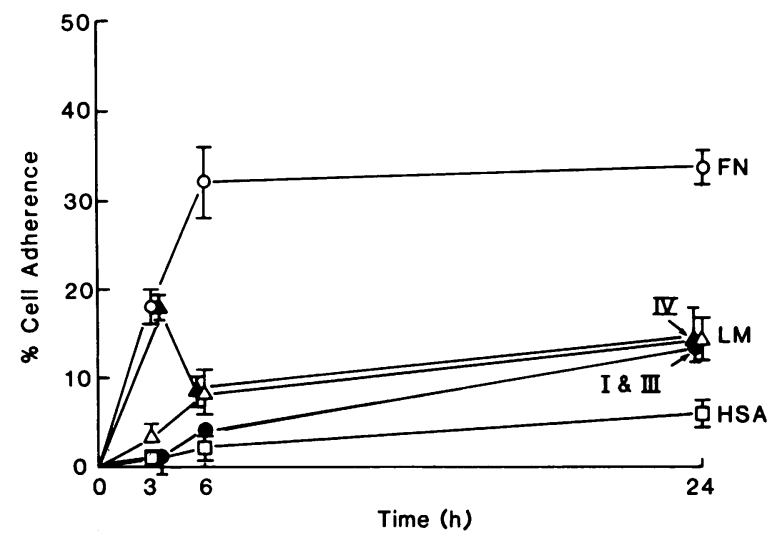

Figure 2. Time course of type II cells adherence on FN, LM, types I and III collagen, type IV collagen and HSA-coated surfaces. Bacteriologic plastic, flat-bottom, $6 \mathrm{~mm}$ diam, microtiter wells were precoated with $100 \mu \mathrm{g} / \mathrm{ml} \mathrm{FN}, \mathrm{LM}$, or collagen, and $20 \mathrm{mg} / \mathrm{ml} \mathrm{HSA}$. Plates coated with FN, LM, or collagen were subsequently incubated with 20 $\mathrm{mg} / \mathrm{ml}$ HSA to block all plastic binding sites for proteins (see Methods). Aliquots of $100 \mu \mathrm{l}$ freshly isolated rat alveolar type II epithelial cells at a concentration of $6 \times 10^{5}$ cells $/ \mathrm{ml}$ were plated in the precoated wells and incubated in a $100 \%$ humidified, $95 \%$ air, $5 \% \mathrm{CO}_{2}$ atmosphere at $37^{\circ} \mathrm{C}$ for the times indicated. Nonadherent cells were washed away with a gentle stream of PBS, generated by a constant hydrostatic pressure head. The nuclei of adherent cells were released with Zapoglobin and counted on a Coulter counter. Percent adherence represents the quotient of adherent cell number divided by the number of cells added to each well $\times 100$. The abscissa represents the time of type II cell incubation with the protein coated surfaces. Each point is the mean of four replicate wells \pm standard error of the mean (SEM). The experiment shown is representative of three experiments except the two other experiments showed a slight increase in type II cell adherence on FN between 6 and $24 \mathrm{~h}$.

MoAb were preincubated with the protein-coated wells and then washed just prior to assay (data not shown); therefore, all experiments illustrated in Fig. 7 were done with MoAb preincubation of microtiter plates plus coincubation with the cells during the adherence assay. Both time and preincubation constraints on monoclonal antibody inhibition experiments serve to exemplify the decreased capacity of MoAb to interfere with functional assays compared with polyclonal antibodies.

\section{Discussion}

Rat type II cells adhere (Fig. 2) and spread (Fig. 1) very slowly compared with human epidermal cells (32) or human fibroblasts (21, R. A. F. Clark, personal observations). For example, epidermal cells and fibroblasts reach 50\% maximal adhesion in 15 to $30 \mathrm{~min}$ and maximum adhesion by $1 \mathrm{~h}$. In addition, attached type II cells spread slowly over a 6-d period of time to extremely large cell diameters on FN substrates (K. Sugahara, R. J. Mason, and R. A. F. Clark, unpublished data) while human epidermal cells (32) and human fibroblasts (33) spread rapidly (15 min to $3 \mathrm{~h}$ ) and to much smaller cell diameters on FN. Type II cells spread even more slowly on laminin (see below) and type I and III collagen and to smaller final cell diameters (K. Sugahara, R. J. Mason, and R. A. F. Clark, unpublished data). Since human type II cells also adhere and spread slowly on similar substrates
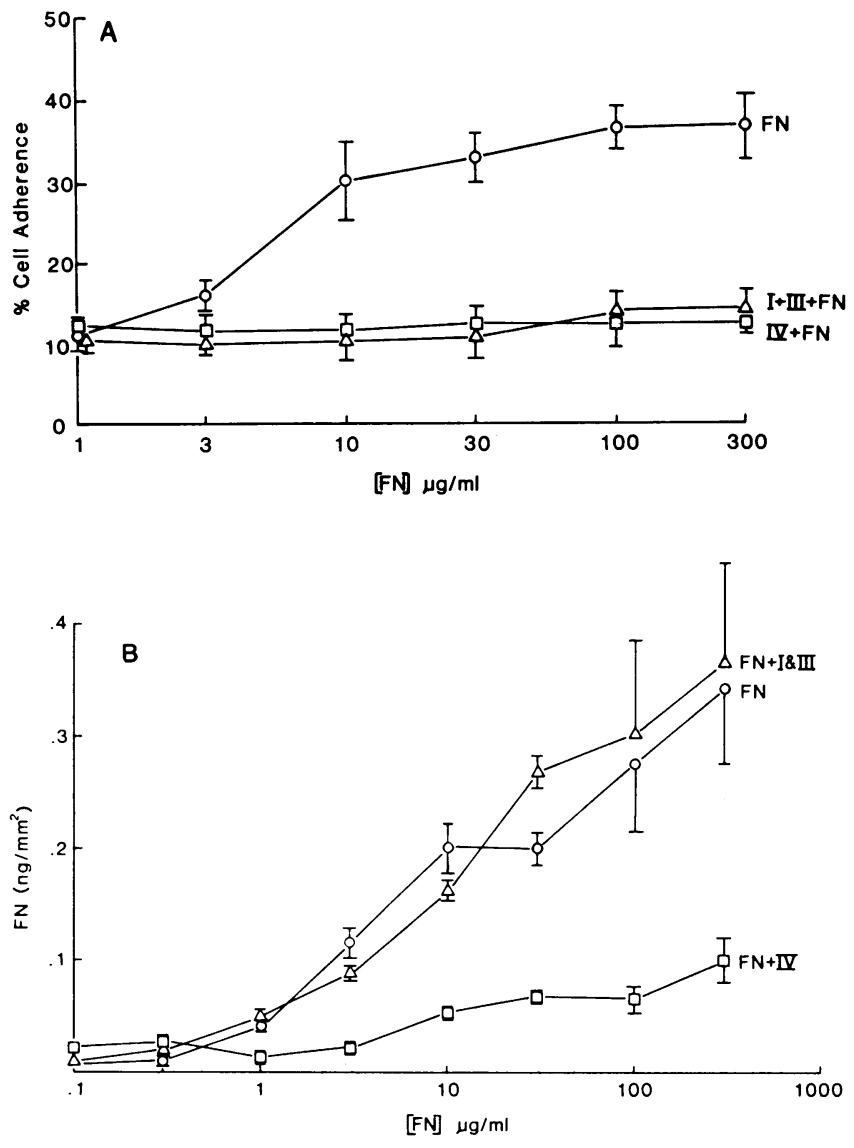

Figure 3. (A) Dose response of type II cell adherence on FN-coated and FN/collagen-coated surfaces. Experiments were performed as described in Fig. 2, except cells were plated in microtiter wells precoated with human FN, or collagen followed by FN (see Methods), and incubated for $24 \mathrm{~h}$. Percent adherence represents the quotient of adherent cell number divided by the number of cells added to each well $\times 100$. The abscissa represents the FN concentration used to precoat the microtiter wells. Three separate experiments were done and within each experiment quadruplicate wells were used for each FN concentration assayed. Each point represents the mean of the three means \pm SEM. $(B)$ Quantitation of FN adsorbed to plastic or collagen-coated surfaces and available for subsequent protein-FN and cell-FN interactions. FN was adsorbed directly onto bacteriologic plastic, 16-mm diam, flat-bottom wells or adsorbed to well precoated with types I and III collagen or type IV collagen. A modified inhibition ELISA was used to measure the surface density of FN on these wells (see Methods). Three separate experiments were done and within each experiment quadruplicate wells were used for each FN concentration assayed. Each point represents the mean of the three means \pm SEM.

(R. J. Mason, personal observation), this appears to be a cell type, not a species characteristic. The gradual rise in adherent cell number was not secondary to cell proliferation since significant DNA synthesis does not occur in type II cell cultures under these conditions (34). Perhaps type II cells need to regenerate cell surface receptors, which are critical for cell attachment and spreading, but are removed by elastase during the isolation procedure. From type II cell adherence experiments performed while protein synthesis was blocked, this appewrs to be true, at least in part. In these experiments, freshly isolated rat type II cells, incubated in 2.5 or $25 \mu \mathrm{g} / \mathrm{ml}$ cycloheximide during adherence 

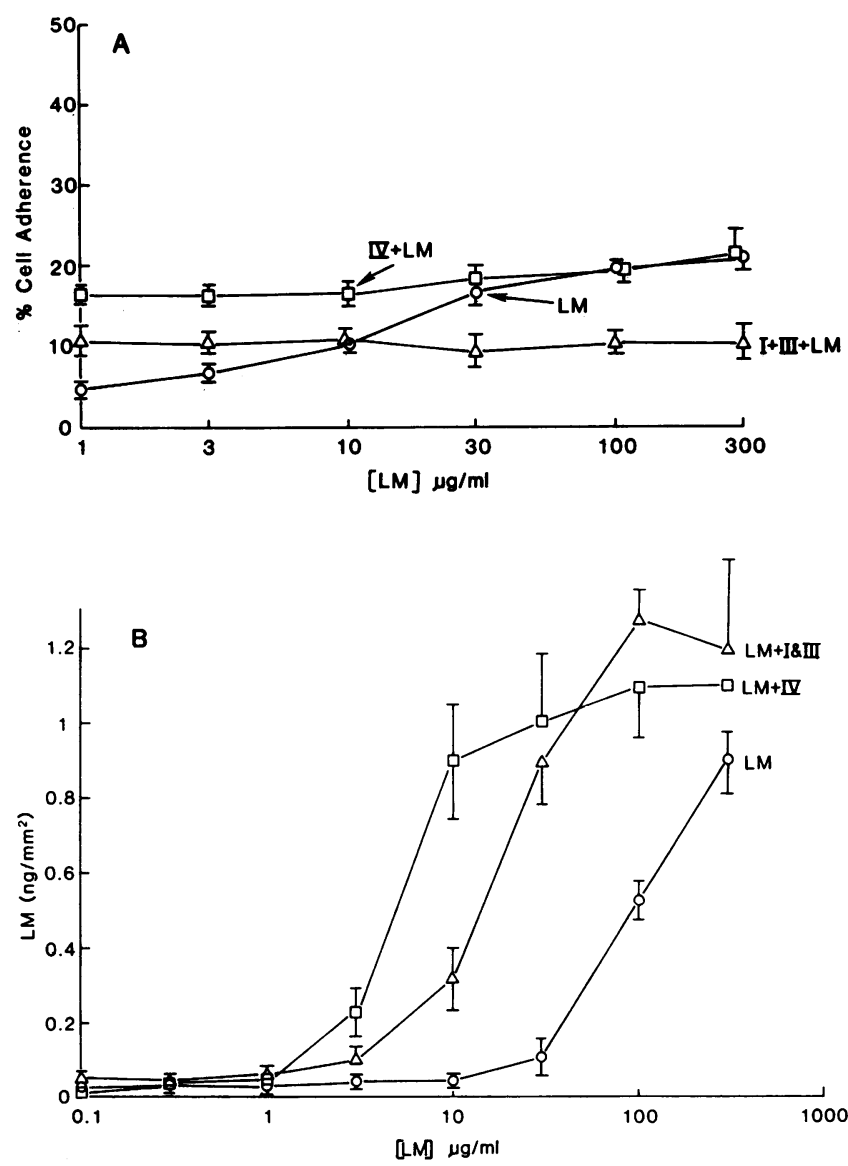

Figure 4. (A) Dose response of type II cell adherence on LM-coated and LM/collagen-coated surfaces. Experiments were performed as described in Fig. 2, except cells were plated in microtiter wells, precoated with LM, or collagen followed by LM (see Methods), and incubated for $24 \mathrm{~h}$. Percent adherence represents the quotient of adherent cell number divided by the number of cells added to each well $\times 100$. The abscissa represents the LM concentration used to precoat the microtiter wells. Three separate experiments were done and within each experiment quadruplicate wells were used for each LM concentration assayed. Each point represents the mean of the three means \pm SEM. (B)Quantitation 'of LM adsorbed to plastic or collagen-coated surfaces and available for subsequent protein-LM and cell-LM interactions. LM was adsorbed directly onto bacteriologic plastic, $16-\mathrm{mm}$ diam, flat-bottom wells or adsorbed to wells precoated with types I and III collagen or type IV collagen. A modified inhibition ELISA was used to measure the surface density of LM on these wells (see Methods). Three separate experiments were done and within each experiment quadruplicate wells were used for each FN concentration assayed. Each point represents the mean of the three means \pm SEM.

assays, showed a $40-60 \%$ reduction in adherence whether the cells were plated on FN, LM, or types I and III collagen (data not shown). Thus, some de novo protein synthesis is required for maximum adherence on any substrate. This protein may either be the cell surface receptor for the substrates tested or some protein needed to link the cell surface to the substrates (a protein with lectinlike activity). Whether other important reasons such as cell metabolic activity underlie the slow adhesion and spreading of type II is currently not known. However, phospholipid synthesis as measured by incorporation of acetate, palmi- tate, and glucose is higher in freshly isolated cells than cells cultured for $1 \mathrm{~d}$.

Since these time course adherence experiments demonstrated that FN was a better substrate for type II cells adherence than LM, types I and III collagen, type IV collagen or HSA, the question arose whether this occurred simply because fibronectin was adsorbed onto the plastic wells in greater quantities. This question can be directly addressed by radiolabeling each protein with ${ }^{125} I$ and measuring its surface adsorption. An even more important question, however, is whether more fibronectin than other proteins is available on the surface for subsequent protein-cell interactions. Experiments utilizing radiolabeled proteins do not address this question since they measure total adsorption and therefore do not distinguish between a protein monolayer, in which all protein is available for subsequent interactions, or a protein sandwich, in which the protein is multilayered on a surface and the lower layers are not available for subsequent interactions. To approach this latter, more important question we modified the inhibition ELISA to quantitate the amount of surface adsorbed proteins available for antibody binding (see Methods). The surface adsorbed protein measured in this fashion is expressed in nanograms per square millimeter and entitled protein surface density. FN and LM were selected for these studies since they are of great biologic interest and since they both bind to collagens. The latter characteristic gave us the opportunity to measure the surface density of FN and LM on two types of collagen as well as on plastic. Experiments were constructed so that cell adherence on FN and LM could be directly compared to FN and LM surface densities as well as to each other. As shown in Fig. $3 A$, type II cells adhered increasingly well to plastic coated with increasing concentrations of FN. This correlated well with increasing FN surface densities (Fig. 3 B). Likewise, the lack of type II cell adherence to plates coated with FN/ type IV collagen (Fig. $3 A$ ) correlated well with low FN surface densities at all concentrations of FN used to precoat the plates (Fig. 3 B).

Interestingly, there was a disparity between the poor type II cell adherence and the increasing FN surface densities on type I and III collagen seen with increasing FN concentrations used to coat the plates (Fig. $3 \mathrm{~B}$ ). Even though FN molecules were available on the plate surface, the FN cell-binding domain (35, 36) might not be available. This explanation is, in fact, probably too simplistic since both human epidermal cells (32), and human microvascular cells (37) attach equally well to FN on plastic and FN on types I and III collagen while they bind less well to FN on type IV collagen. Thus, the attachment of these other epithelial cell types to FN correlates with the surface density of FN adsorbed to the various surfaces. Only the type II alveolar epithelial cell demonstrates a disparity between cell attachment to FN on types I and III collagen and surface density of FN on types I and III collagen. Perhaps, a fibronectin determinate, in addition to the cell binding domain, is necessary for maximal type II cell attachment to FN. This appears to be true for certain types of melanoma cells (38). We have attempted to investigate these questions by quantitating the expression of the cell-binding and other domains of fibronectin when fibronectin was adsorbed to different surfaces by utilizing inhibition ELISA assays with monoclonal antibodies to these various regions of fibronectin. Unfortunately these assays were too insensitive to give meaningful results. A monoclonal antibody based inhibition ELISA 


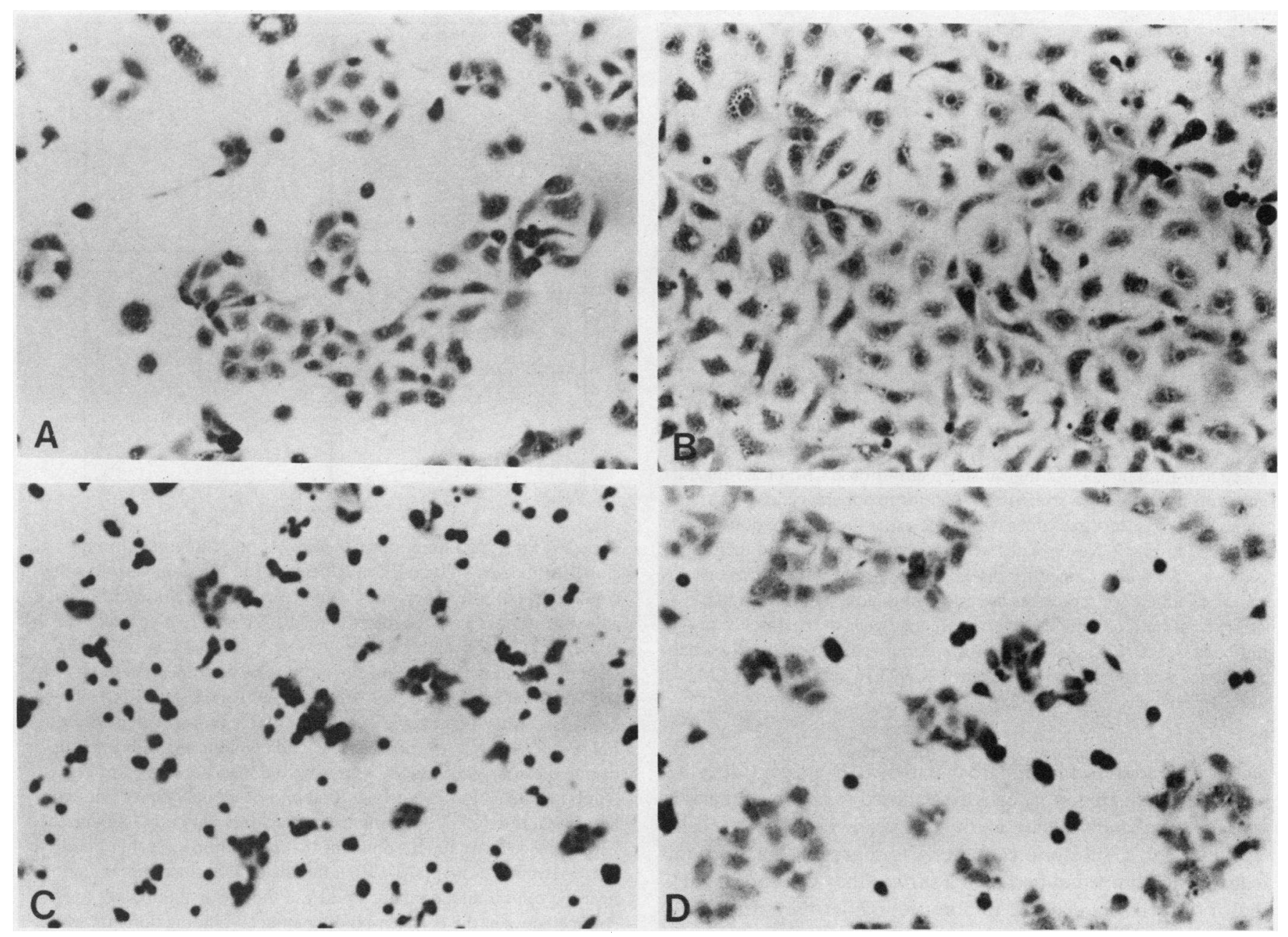

Figure 5. Photomicrographs of adherent rat lung type II epithelial cells on FN $(A$ and $B)$ and LM $(C$ and $D)$ substrate at $24 \mathrm{~h}(A$ and $C)$ and at 48 $\mathrm{h}(B$ and $D)$ after plating. Cells were fixed with methanol, stained by the Papanicolaou procedure, and observed at 6,000 magnification.

is probably less sensitive than a polyclonal antibody based ELISA secondary to only one antibody binding per protein antigen in the former compared to multiple antibodies binding per protein antigen in the latter.

Type II cells adhered poorly on all LM coated surfaces (Fig. $4 A$ ), even at surface densities three to four times higher (Fig. 4 $B$ ) than FN surface densities (Fig. $3 B$ ) that supported good adherence (Fig. $3 \mathrm{~A}$ ). These experiments thus suggest that there is an intrinsic difference in the ability of FN and LM to support type II cell adherence.

The degree of type II cell spreading on FN- and LM-coated surfaces (Fig. 5) seems to parallel type II cell adherence on these protein substrata (Figs. $3 A$ and $4 A$ ). Type II cells are greatly spread on FN by $24 \mathrm{~h}$ (Fig. $5 \mathrm{~A}$ ), whereas they are spread to a much lesser degree on LM at this time (Fig. $5 C$ ). In fact, the degree of type II cell spreading on LM at $24 \mathrm{~h}$ (Fig. $5 \mathrm{C}$ ) is more comparable to the degree of spreading on $\mathrm{FN}$ at $6 \mathrm{~h}$ (Fig. $1 E$ ). By $48 \mathrm{~h}$ type II cells are well spread on LM-coated surfaces (Fig. $5 \mathrm{D}$ ) but the cells still show greater spreading on FN (Fig. $5 B$ ).

Specificity of type II cell adherence on FN, LM, and FG is illustrated in Fig. 6 by cross-blocking experiments with antibodies to these proteins. In addition, type II cell adherence on FN was dependent on the fibroblast cell-attachment domain as determined by blocking studies with a monoclonal antibody to this determinant (Fig. 7). Previous studies have localized fibroblast attachment to $\mathrm{FN}$ to an $11-\mathrm{kD}$ domain that is two-thirds the distance from the amino-terminus toward the carboxy terminus of the molecule $(35,36)$. Monoclonal antibodies to other regions of the molecule failed under all assay conditions to inhibit type II cell adherence to FN (Fig. 7). Thus, it appears that epithelial cells as well as fibroblasts may attach to $\mathrm{FN}$ at the same molecular domain.

In some previous studies (10-12) investigators failed to demonstrate that $\mathrm{FN}$ was an adhesive protein for epidermal cells. However, two of these studies examined epidermal cell adherence on FN substrates prepared by absorption from low $(10 \mu \mathrm{g} / \mathrm{ml}$ or less) concentrations of $\mathrm{FN}(10,11)$. More recent investigations $(32,39,40)$ have shown that epidermal cells require substrates prepared from higher concentrations ( $30 \mu \mathrm{g} / \mathrm{ml}$ or more) of FN. The third study quantitated spreading not attachment (12) and demonstrated that $\mathrm{FN}$ at concentrations up to $300 \mu \mathrm{g} / \mathrm{ml}$ did not induce epidermal cell spreading. In contrast, subsequent investigations $(32,40,41)$ showed that FN substrates prepared at concentrations above $30 \mu \mathrm{g} / \mathrm{ml}$ could mediate spreading. Stenn 


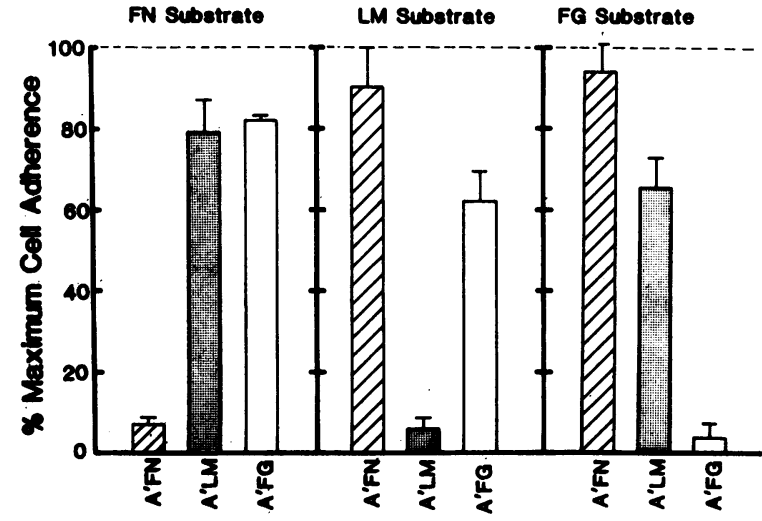

Figure 6. Specific antibody blocking of type II cell adherence to FN, $\mathrm{LM}$, and FG. Precoated wells were incubated with either $1.8 \mathrm{mg} / \mathrm{ml}$ sheep anti-human FN, $4.2 \mathrm{mg} / \mathrm{ml}$ sheep anti-mouse $\mathrm{LM}$, or $2.5 \mathrm{mg} / \mathrm{ml}$ goat anti-human FG overnight at $4^{\circ} \mathrm{C}$ prior to adherence assays. After plates were washed three times with PBS, experiments were done as described in Fig. 2 except plates were incubated for $24 \mathrm{~h}$ and then the cells were fixed and stained for visual counts (see Methods). Percent maximal adherence represents the quotient of adherent cells in the presence of antibody divided by the adherent cells in the absence of antibody $\times 100$. Each bar is the mean of four replicate wells. Maximal adherence was $509 \pm 58$ cells $/ \mathrm{mm}^{2}$ for $\mathrm{FN}, 92 \pm 16$ cells $/ \mathrm{mm}^{2}$ for $\mathrm{LM}$, and $213 \pm 18$ cells $/ \mathrm{mm}^{2}$ for FG.

et al. (41) address this apparent paradox. It appears that the order in which epidermal cells are exposed to fibronectin and a surface greatly affects their ability to spread. That is, if the cells are added to a substrate containing fibronectin or a medium containing fibronectin and then a surface they will spread (41), but if the cells are exposed to fibronectin after they attach to a surface, they will not spread (12). Other epithelial cells have been shown to adhere and spread on fibronectin substrates, including hepatocytes from both the rat $(42,43)$ and the mouse (44), rabbit intestinal epithelial cells (45), and human amnion epithelial cells (46). Rat alveolar type II cells are quite unlike epidermal cells but quite like hepatocytes in that they adhere to low $(2-5 \mu \mathrm{g} / \mathrm{ml})$ concentrations of adsorbed FN. Like type II alveolar epithelial cells, human amnion epithelial cells (46) and human epidermal cells (47) have been recently observed to spread on both FN and collagen substrates whereas they show incomplete spreading on laminin (47). Using a phagokinetic assay, O'Keefe et al. (47) demonstrated that the ability of epidermal cells to spread appeared to be related to their ability to migrate.

We believe that plating type II cells onto protein coated microtiter wells more closely represents the reepithelialization process of postalveolar injury, such as occurs in the adult respiratory distress syndrome, than epithelial adhesion to basement membrane (BM) for several reasons: $(a)$ the protein coats in these experiments provide a rather simple matrix more like an injured alveolar surface (5) rather than the complex, highly ordered BM (48); (b) freshly plated alveolar type II cells attempt to cover the surface of a plastic well much like migrating type II cells attempt to repave the surface of an injured alveolus; (c) cultured type II alveolar epithelial cells gradually assume the phenotypic characteristics that one might expect for type II cells developing into type I cells after lung injury; that is, they decrease phosphatidylglycerol and disaturated phosphatidylcholine synthesis (49), they have a marked accumulation of actin bundles in their pe-

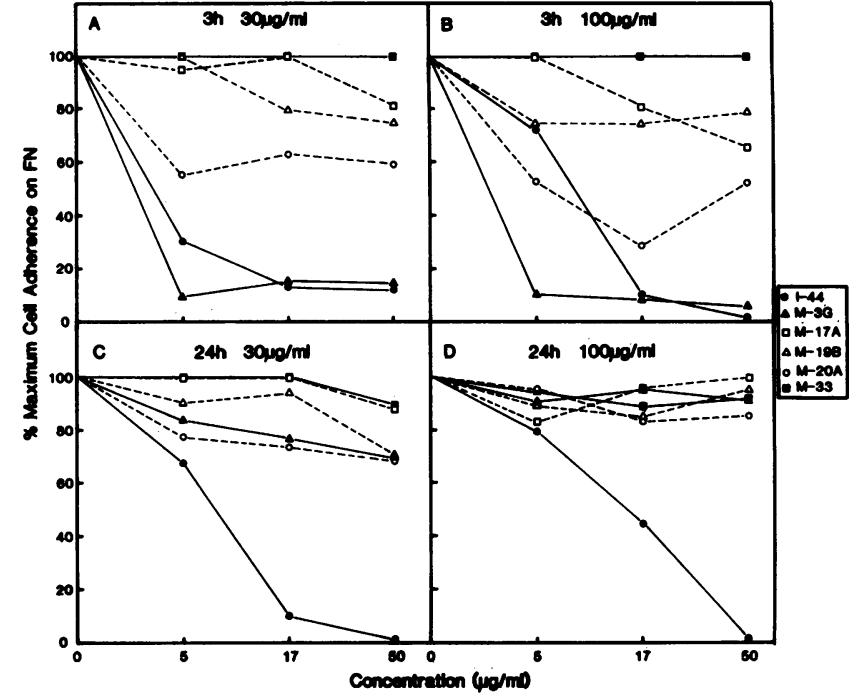

Figure 7. Effect of affinity purified anti-FN polyclonal and monoclonal antibodies on type II cell adherence to $\mathrm{FN}$ under various assay conditions. ( $A$ ) Microtiter wells were precoated with $30 \mu \mathrm{g} / \mathrm{ml} \mathrm{FN} \mathrm{and}$ adherence assays were incubated $3 \mathrm{~h}$. $(B)$ Wells were precoated with $100 \mu \mathrm{g} / \mathrm{ml} \mathrm{FN}$ and adherence assays were incubated $3 \mathrm{~h}$. $(C)$ Wells were precoated with $30 \mu \mathrm{g} / \mathrm{ml} \mathrm{FN}$ and assays were incubated for $24 \mathrm{~h}$. (D) Wells were precoated with $100 \mu \mathrm{g} / \mathrm{ml} \mathrm{FN}$ and assays were incubated for $24 \mathrm{~h}$. All antibody preparations were preincubated with the FN precoated wells overnight at $4^{\circ} \mathrm{C}$ and coincubated with the cells during the adherence assays. Assays were done as described in Fig. 6. Antibodies to FN included I-44, a rabbit polyclonal affinity purified anti-FN antibody; $\mathrm{M}-3 \mathrm{G}$, a mouse monoclonal antibody to an epitope within the cell-attachment domain; M-17A, a monoclonal antibody to the N-terminal domain; M-19B, a monoclonal antibody to an epitope near the cell-binding domain; M-20A, a monoclonal antibody to an epitope between the collagen-binding and cell-binding domain; M-33, a monoclonal antibody to the C-terminal domain. Percent maximal adherence represents the quotient of adherent cell number in the presence of antibody divided by the number of adherent cells in the absence of antibody $\times 100$. The abscissa represents the anti-FN antibody concentration. Each point is the mean of four replicate wells. Maximal adherence was $116 \pm 24$ cells $/ \mathrm{mm}^{2}$ in $(A), 111 \pm 18 \mathrm{cell} / \mathrm{mm}^{2}$ in $(B)$, $464 \pm 54$ cells $/ \mathrm{mm}^{2}$ in $(C)$, and $916 \pm 29$ cells $/ \mathrm{mm}^{2}$ in $(D)$.

riphery (K. Sugahara, R. J. Mason, and R. A. F. Clark, unpublished data), and they spread to enormous cell diameters (K. Sugahara, R. J. Mason and R. A. F. Clark, unpublished data). Since epithelial adhesion to the normal BM must be a complex interaction as illustrated by the inherent complexity of the BM at the ultrastructural level (48), it is not surprising that type II cells adhere and spread poorly on a haphazard matrix of purified laminin (Figs. $4 A$ and $5 C, D$ ). Our observation that type II cells attach and spread poorly on laminin implies that laminin does not direct the spreading that occurs after loss of type I cells in lung injury. Nevertheless, laminin may be very important in the maintenance of type II cells production of surface active material on normal BM.

In summary, the ability of rat alveolar type II epithelial cells to adhere and spread on FN in vitro support the hypothesis that the FN matrix observed beneath migrating and proliferating type II cells during alveolar reepithelialization after lung injury plays an important role in the reepithelialization process, perhaps by providing an extracellular matrix that promotes cell mobility compared with normal BM, which promotes tenacious adhesion. 


\section{Acknowledgments}

We appreciate the technical assistance of Laura Rokosz, the typing assistance of Marialyce Austin, and the photoillustration work of Barry Silverstein.

This work was supported by National Institutes of Health grants AM31514 to R. A. F. Clark, Special Center of Research on Interstitial Lung Disease (HL27353) to R. J. Mason, and HL26009 and HL29594 to J. A. McDonald.

\section{References}

1. Kuhn, C., III. 1982. The cytology of the lung: Ultrastructure of the respiratory epithelium and the extracellular lining layers. In Lung Development: Biological and Clinical Perspectives. Vol. I. Academic Press, Inc., New York.

2. Evans, M. J., L. J. Cabral, R. J. Stephens, and G. Freeman. 1973 Renewal of alveolar epithelium in the rat following exposure to $\mathrm{NO}_{2}$. Am. J. Pathol. 70:175-198.

3. Evans, M. J., L. J. Cabral, R. J. Stephens, and G. Freeman. 1975 Transformation of alveolar type 2 cells into type 1 cells following exposure to $\mathrm{NO}_{2}$. Exp. Mol. Pathol. 22:142-150.

4. McDonald, J. A., B. Villiger, T. Broekelmann, C. Kuhn, and C. Torikata. 1981. Human lung fibronectin: Ultrastructural localization by immunohistochemistry. Clin. Res. 29:449A. (Abstr.)

5. Torikata, C., B. Villiger, C. Kuhn III, and J. A. McDonald. 1985. Ultrastructural distribution of fibronectin in normal and fibrotic human lung. Lab. Invest. 52:399-408.

6. Clark, R. A. F., J. M. Lanigan, P. Dellapella, E. Manseau, H. F. Dvorak, and R. B. Colvin. 1982. Fibronectin and fibrin provide a provisional matrix for epidermal migration during wound re-epithelialization. J. Invest. Dermatol. 79:264-269.

7. Repesh, L. A., T. J. Fitzgerald, and L. T. Furcht. 1982. Fibronectin involvement in granulation tissue and wound healing in rabbits. J. Histochem. Cytochem. 30:351-358.

8. Repesh, L. A., T. J. Fitzgerald, and L. T. Furcht. 1982. Changes in distribution of fibronectin during limb regeneration in newts using immunocytochemistry. Differentiation. 22:125-131.

9. Fujikawa, L. S., C. S. Foster, T. J. Harrist, J. M. Lanigan, and R. B. Colvin. 1981. Fibronectin in healing rabbit corneal wounds. Lab. Invest. 45:120-128.

10. Murray, J. C., G. Stingl, H. K. Kleinman, G. R. Martin, and S. I. Katz. 1979. Epidermal cells adhere preferentially to type IV (basement membrane) collagen. J. Cell Biol. 80:197-202.

11. Terranova, V. P., D. H. Rohrback, and G. R. Martin. 1980. Role of laminin in attachment of PAM 212 (epithelial) cells to basement membrane collagen. Cell. 22:719-726.

12. Federgreen, W., and K. S. Stenn. 1980. Fibronectin (LETS) does not support epithelial cell spreading. J. Invest. Dermatol. 75:261-263.

13. Dobbs, L. G., and R. J. Mason. 1979. Pulmonary alveolar type II cells isolated from rats. Release of phosphatidylcholine in response to $\beta$-adrenergic stimulation. J. Clin. Invest. 63:378-387.

14. Dobbs, L. G., E. F. Geppert, M. C. Williams, R. D. Greenleaf, and R. J. Mason. 1980. Metabolic properties and ultrastructure of alveolar type II cells isolated with elastase. Biochim. Biophys. Acta. 618:510-523.

15. Dobbs, L. G., R. J. Mason, M. C. Williams, B. J. Benson, and K. Sucishi. 1982. Secretion of surfactant by primary cultures of alveolar type II cells. Biochim. Biophys. Acta. 713:118-127.

16. Furie, M. B., and D. B. Rifkin. 1980. Proteolytically derived fragments of human plasma fibronectin and their location within intact molecules. J. Biol. Chem. 255:3134-3140.

17. Clark, R. A. F., H. F. Dvorak, and R. B. Colvin. 1981. Fibronectin in delayed-type hypersensitivity skin reactions: Associations with vessel permeability and endothelial cell activation. J. Immunol. 126:783-793.

18. Timpl, R., H. Rohde, P. G. Robey, S. I. Rennard, J. M. Foidart and G. R. Martin. 1979. Laminin-A glycoprotein from basement membranes. J. Biol. Chem. 254:9933-9937.

19. Timpl, R., G. R. Martin, P. Bruckner, G. Wick, and H. Weideman. 1978. Nature of the collagenous protein in a tumor basement membrane. Eur. J. Biochem. 84:43-52.

20. Engvall, E., and E. Ruoslahti. 1977. Binding of soluble form of fibroblast surface protein, fibronectin, to collagen. Int. J. Cancer 20:1-5.

21. Grinnell, F., and D. Minter. 1978. Attachment and spreading of baby hamster kidney cells to collagen substrata: effects of cold-insoluble globulin. Proc. Natl. Acad. Sci. USA. 75:4408-4412.

22. Rauvala, H., W. G. Carter, and S. I. Hakomori. 1981. Studies of cell adhesion and recognition. I. Extent and specificity of cell adhesion triggered by carbohydrate-reactive proteins (glycosidases and lectins) and by fibronectin. J. Cell Biol. 88:127-137.

23. Grinnell, F., and M. K. Feld. 1981. Adsorption characteristics of plasma fibronectin in relationship to biological activity. J. Biomed. Mater. Res. 15:363-381.

24. Rennard, S. I., R. Berg, G. R. Martin, J. M. Foidart, and P. Behron Robey. 1980. Enzyme-linked immunoassay (ELISA) for connective tissue components. Anal. Biochem. 104:205-214.

25. Butler, W. B. 1984. Preparing nuclei from cells in monolayer culture suitable for counting and for following synchronized cells through the cell cycle. Anal. Biochem. 141:70-73.

26. Crowle, A. J. 1973. Immunodiffusion. Academic Press, Inc., New York. 85-90.

27. Williams, C. A., and M. W. Chase. 1967. Methods of Immunology and Immunochemistry. Academic Press, Inc., New York. 1:422.

28. McDonald, J. A., and D. G. Kelley. 1984. Specific binding of fibronectin-anti-fibronectin immune complexes to procollagen: A new pitfall in immunostaining. J. Cell Biol. 98:1042-1047.

29. Kikkawa, Y., and K. Yoneda. 1974. The type II epithelial cell of the lung. I. Method of isolation. Lab. Invest. 30:76-84.

30. Sun, T.-T., and H. Green. 1978. Keratin filaments of cultured human epidermal cells. J. Biol. Chem. 253:2053-2060.

31. Sun, T.-T., C. Shih, and H. Green. 1979. Keratin cytoskeletons in epithelial cells of internal organs. Proc. Natl. Acad. Sci. (USA). 76: 2813-2817.

32. Clark, R. A. F., J. M. Folkvord, and R. L. Wertz. 1985. Fibronectin mediates human keratinocyte adherence. J. Invest. Dermatol. 85:378383.

33. Grinnell, F., and M. K. Feld. 1979. Initial adhesion of human fibroblasts in serum-free medium: Possible role of secreted fibronectin. Cell. 17:117-129.

34. Leslie, C. C., K. McCormick-Shannon, P. C. Robinson, and R. J. Mason. 1985. Stimulation of DNA synthesis in cultured rat alveolar type II cells. Exp. Lung Res. 8:53-66.

35. Pierschbacher, M. D., E. G. Hayman, and E. Ruoslahti. 1981. Localization of the cell-attachment site in FN with monoclonal antibodies and proteolytic fragments of the molecule. Cell. 26:259-267.

36. Pierschbacher, M. D., E. Ruoslahti, J. Sundelin, P. Lind, and P. A. Peterson. 1982. The cell attachment domain of FN. Determination of the primary structure. J. Biol. Chem. 257:9593-9597.

37. Clark, R. A. F., J. M. Folkvord, and L. D. Nielsen. 1986. Either exogenous or endogenous fibronectin can promote adherence of human endothelial cells. J. Cell Sci. (In press).

38. McCarthy, J. B., S. T. Hagen, and L. T. Furcht. 1986. Human fibronectin contains distinct adhesion- and motility-promoting domains for metastatic melanoma cells. J. Cell Biol. 102:179-188.

39. Gilchrest, B. A., J. K. Calhoun, and T. Maciag. 1982. Attachment and growth of human keratinocytes in a serum-free environment. $J$. Cell. Physiol. 112:197-206.

40. Takashima, A., and F. Grinnell. 1984. Human keratinocyte adhesion and phagocytosis promoted by fibronectin. J. Invest. Dermatol. 83:352-358.

41. Stenn, K. S., J. A. Madri, T. Tinghitella, and V. P. Terranova. 1983. Multiple mechanisms of dissociated epidermal cell spreading. $J$. Cell Biol. 96:63-67. 
42. Hook, M., K. Rubin, A. Oldberg, B. Obrink, and A. Vaheri. 1977. Cold-insoluble globulin mediates the adhesion of rat liver cells to plastic petri dishes. Biochem. Biophys. Res. Commun. 79:726-733.

43. Johansson, S., and M. Hook. 1984. Substrate adhesion of rat hepatocytes. On the mechanisms of attachment of fibronectin. J. Cell Biol. 98:810-817.

44. Carlsson, R., E. Engvall, A. Freeman, and E. Ruoslahti. 1981. Laminin and fibronectin in cell adhesion. Enhanced adhesion of cells from regenerating liver to laminin. Proc. Natl. Acad. Sci. USA. 78:24032406.

45. Burrill, P. H., I. Bernardini, H. K. Kleinman, and N. Kretchmer. 1981. Effect of serum, fibronectin, and laminin on adhesion of rabbit intestinal epithelial cells in culture. J. Supramol. Struct. Cell. Biochem. 16:385-392.
46. Aplin, J. D., S. Campbell, and L. J. Foden. 1984. Adhesion of human amnion epithelial cells to extracellular matrix. Evidence for multiple mechanisms. Exp. Cell. Res. 153:425-438.

47. O'Keefe, E. J., R. E. Payne, N. Russell, and D. T. Woodley. 1985. Spreading and enhanced motility of human keratinocytes on fibronectin. J. Invest. Dermatol. 85:125-130.

48. Laurie, G. W., C. P. Leblond, and G. R. Martin. 1982. Localization of type IV collagen, laminin, heparan sulfate proteoglycan, and fibronectin to the basal lamina of basement membranes. J. Cell Biol. 95:340-344.

49. Mason, R. J., and L. G. Dobbs. 1980. Synthesis of phosphatidylcholine and phosphatidylglycerol by alveolar type II cells in primary culture. J. Biol. Chem. 255:5101-5107. 